\title{
EFFICIENCY OF HEALTH INVESTMENT: EDUCATION OR INTELLIGENCE?
}

\author{
GOVERT E. BIJWAARD ${ }^{\mathrm{a}, \mathrm{b}, *}$ and HANS VAN KIPPERSLUIS ${ }^{\mathrm{c}, \mathrm{de}}$ \\ ${ }^{a}$ Netherlands Interdisciplinary Demographic Institute (NIDI-KNAW/University of Groningen) Groningen, The Netherlands \\ ${ }^{\mathrm{b}}$ IZA, Bonn, Germany \\ ${ }^{\mathrm{c}}$ Erasmus School of Economics, Erasmus University Rotterdam, Rotterdam, The Netherlands \\ ${ }^{\mathrm{d}}$ Department of Economics, Chinese University of Hong Kong, Hong Kong, China \\ ${ }^{\mathrm{e}}$ Tinbergen Institute, Amsterdam, The Netherlands
}

\section{SUMMARY}

In this paper, we hypothesize that education is associated with a higher efficiency of health investment, yet that this efficiency advantage is solely driven by intelligence. We operationalize efficiency of health investment as the probability of dying conditional on a certain hospital diagnosis and estimate a multistate structural equation model with three states: (i) healthy, (ii) hospitalized, and (iii) death. We use data from a Dutch cohort born around 1940 that links intelligence tests at age 12 years to later-life hospitalization and mortality records. The results indicate that intelligent individuals have a clear survival advantage for most hospital diagnoses, while the remaining disparities across education groups are small and not statistically significant. (C) 2016 The Authors. Health Economics Published by John Wiley \& Sons Ltd.

Received 1 October 2015; Revised 4 March 2016; Accepted 31 March 2016

JEL classification: C41; I14; I24

KEY WORDS: education; intelligence; health; multistate duration model

\section{INTRODUCTION}

Health disparities across educational groups are widespread, and - strikingly - growing over time (Meara et al., 2008). While there has been considerable progress in recent years in unraveling the direction of causality (Grossman, 2015), much less attention has been devoted to understanding the mechanisms through which the higher educated peers achieve their health advantage. As a result, there is no conclusive evidence about why the higher educated peers are healthier than their less-educated peers (Cutler and Lleras-Muney, 2008; Mazumder, 2012; Grossman, 2015).

One often cited hypothesis is that the higher educated peers are more efficient producers of health investment. This could be due to (i) 'productive efficiency' or (ii) 'allocative efficiency'. The former hypothesis posits that higher education leads to a higher marginal product of a given set of health inputs (Grossman, 1972; Michael and Becker, 1973). In simple terms, the higher educated peers understand the doctor better and use existing medical care more efficiently. The allocative efficiency hypothesis on the other hand argues that higher educated individuals choose different, more efficient inputs into health investment, typically thought to be

\footnotetext{
*Correspondence to: Netherlands Interdisciplinary Demographic Institute (NIDI-KNAW/University of Groningen), The Hague, The Netherlands. E-mail: bijwaard@nidi.nl

This is an open access article under the terms of the Creative Commons Attribution License, which permits use, distribution and reproduction in any medium, provided the original work is properly cited.
} 
caused by better health knowledge and a more receptive attitude towards new information (Rosenzweig and Schultz, 1981; Muurinen, 1982).

While there is empirical evidence that higher educated individuals are more efficient users of health investment in terms of both productive and allocative efficiency (see Grossman, 2006 for an excellent review), it is not established whether this is actually the result of education per se. This is surprising for two reasons. First, much of the reasoning why higher educated individuals would be more efficient users of health investment equally holds for intelligence. For example, understanding the doctor better and adhering to complex treatments may be driven by intelligence rather than education (Gottfredson and Deary, 2004).

Second, our reading of the literature on education and health outcomes is that at least half of the health disparities across educational groups are due to the selection of healthier and more able individuals into higher education (Conti and Heckman, 2010; Conti et al., 2010; Heckman et al., 2014; Bijwaard et al., 2015). ${ }^{1}$ Hence, in recent years, evidence is growing that the presumed health returns to education may be smaller than previously thought, which also raises the question to what extent it is the actual attainment of education that improves health investment efficiency.

In this paper, we aim to answer two questions. First: Is education associated with a higher efficiency of health investment? A higher efficiency of health investment implies a higher level of health given the health investment inputs chosen, either for the same inputs (productive efficiency) or using different inputs (allocative efficiency). We choose to focus on an objective health outcome - survival - and an objective health investment measure - a hospitalization for a given condition. We operationalize efficiency of health investment as a lower probability of dying conditional on being admitted to the hospital for a given diagnosis. While the data do not permit disentangling productive from allocative efficiency, the data do provide a unique opportunity to answer a second question: To what extent is intelligence driving the potential efficiency gains associated with education?

To the best of our knowledge, this second hypothesis is novel. Rejecting or non-rejecting this hypothesis has important policy implications. If educational attainment increases the efficiency of health investment then learning itself and the associated knowledge have non-monetary returns in terms of health and survival gains. If instead most of the efficiency gains derive from intelligence, this suggests that supply-side interventions (e.g., longer consultation time, more explicit prescriptions for lower IQ individuals, or nudging) are more appropriate to reduce population disparities in health and survival.

The data used are from a Dutch cohort study of individuals born around 1940 that links intelligence tests at age 12 years to (i) follow-up surveys including education, and (ii) administrative records regarding hospitalizations between 1995 and 2005 and mortality between 1995 and 2011. We use a theoretical model with a health-state-dependent utility function and stochastic mortality risk to formulate hypotheses. Testing the theoretical hypotheses requires estimating a multistate structural equation model with three states: (i) healthy, (ii) hospitalized, and (iii) death.

The results suggest that the higher educated individuals are more efficient users of health investment: They have a smaller probability to die within 1 year after hospital admittance even conditional on self-reported health and previous diagnoses. However, when accounting for selection into education based on intelligence, most of the efficiency gain is removed. It is mostly intelligent people who have a survival advantage for a given hospital diagnosis. Only for people with respiratory diseases, we found large differences in survival by education even conditional on intelligence. However, at least part of these differences seems to be driven by milder respiratory conditions among the higher educated individuals. In sum, the survival advantage among higher educated individuals derives largely from intrinsic abilities like intelligence, and milder conditions, rather than higher educated individuals being more efficient users of health investment.

This paper is structured as follows. The related literature, theoretical framework, and hypotheses are introduced in Section 2. Section 3 presents the multistate structural equation model to test the theoretical hypotheses.

\footnotetext{
${ }^{1}$ The reasoning is also corroborated by studies exploiting compulsory schooling reforms to establish the causal effect of education on health outcomes, which unanimously show that the causal effect of education on health outcomes is either much smaller than the correlation suggests (Lleras-Muney, 2005; Van Kippersluis et al., 2011; Meghir et al., 2013), or even entirely absent (Albouy and Lequien, 2009; Clark and Royer, 2013).
} 
In Section 4, the Brabant data and the linked register data on hospitalization and mortality are discussed. Section 5 presents the empirical results and robustness checks. Section 6 concludes and provides a discussion of the results.

\section{THEORETICAL FRAMEWORK}

\subsection{Related literature}

There are two related strands of literature that our paper contributes to: (i) the association between education and the efficiency of health investment, and (ii) the relationship between ability, education, and health outcomes. We will discuss each of these literatures and our contributions to them briefly.

Education and efficiency of health investment. There is a number of studies showing direct or indirect evidence that education is associated with a higher efficiency of health investment. Gilleskie and Harrison (1998) estimate a structural production model for self-reported health and provide tentative evidence that suggests both productive and allocative efficiency are at work. Kenkel $(1991 ; 1995)$ provides evidence in favor of productive efficiency. Indirect evidence for allocative efficiency is given by Goldman and Smith (2002), Goldman and Lakdawalla (2005), Lleras-Muney and Lichtenberg (2005), and Glied and Lleras-Muney (2008) who show that higher educated individuals adhere better to, and benefit more from, complex treatments for HIV and diabetes, and sooner adapt to evolving medical technologies, and Lange (2011) who shows that higher educated individuals process objective risk factors for cancer into their subjective probabilities. We contribute to this literature by testing whether the presumed efficiency gains of education are in fact driven by intelligence.

Intelligence, education, and health. It has been recognized for a long time that intelligence influences educational attainment and that this gives rise to the famous 'ability bias' in the returns to education (Griliches, 1977). More recently, studies have also established a strong correlation between intelligence and health outcomes (Auld and Sidhu, 2005; Cutler and Lleras-Muney, 2008; Kaestner and Callison, 2011). The fact that intelligence influences both education and health outcomes has led to a recent series of closely related papers that estimate the extent to which the association between education and health is driven by selection on basis of intelligence and non-cognitive skills (Conti and Heckman, 2010; Conti et al., 2010; Bijwaard et al., 2015). Our contribution to this literature is twofold. First, we extend the structural equation model by Bijwaard et al. (2015) to a multistate duration model, where individuals can be healthy, hospitalized, or deceased. Second, we do not focus on health or mortality, but on the efficiency of health investment, which sheds lights on the mechanisms through which education affects health.

\subsection{Theoretical background and hypotheses}

To structure thoughts, we propose a stylized model, somewhat similar to Murphy and Topel (2006), in which individuals maximize a utility function of the form:

$$
\int_{t=0}^{\infty} U\left\{U_{H}[C(t), L(t)], U_{I}[C(t), L(t)]\right\} P^{(k)}(0, t) e^{-\rho t} d t \quad k=0,1
$$

where $U[\cdot]$ is the utility function with inputs from consumption $C(t)$ and leisure $L(t)$ and $P^{(k)}(0, t)$ is the transition probability for educational level $k$ from age 0 to $t$. We envision a model in which utility per period derived from consumption and leisure is health dependent: $U_{H}[\cdot]$ is the utility when in good health, while $U_{I}[\cdot]$ is the utility when hospitalized. ${ }^{2}$

We assume that in adulthood, there are three different states: (i) being healthy (H), (ii) being hospitalized (I), and (iii) death (D), where utility in death is normalized to zero. Hence, the matrix of transition probabilities $P$

\footnotetext{
${ }^{2}$ Obviously, the individual will also face a budget and time constraint, but analyzing a fully fledged life cycle model is beyond the scope of this paper.
} 
is a three by three matrix where the first row contains the transition probabilities from healthy to healthy, hospitalized, and death $\left\{P_{H H}, P_{H I}, P_{H D}\right\}$, the second row contains the transition probabilities from hospitalized to healthy, hospitalized, and death $\left\{P_{I H}, P_{I I}, P_{I D}\right\}$, and no transitions are possible after death.

We assume that the transition process between the states is a Markov process and that the transition intensities $\lambda(\cdot)$ are constant over an age interval of 1 year but depend on education. The transition rates from healthy to hospitalized $\left(\lambda_{H I}\right)$, hospitalized to health $\left(\lambda_{I H}\right)$, healthy to death $\left(\lambda_{H D}\right)$, and hospitalized to death $\left(\lambda_{I D}\right)$ jointly comprise a matrix of transition intensities

$$
M(t)=\left(\begin{array}{ccc}
-\left(\lambda_{H I}(t)+\lambda_{H D}(t)\right) & \lambda_{H I}(t) & \lambda_{H D}(t) \\
\lambda_{I H}(t) & -\left(\lambda_{I H}(t)+\lambda_{I D}(t)\right) & \lambda_{I D}(t) \\
0 & 0 & 0
\end{array}\right)
$$

In turn, the transition probability matrix from age $s$ to age $t$ is given by the following:

$$
P(s, t)=\exp (M(s))=V \Lambda(t-s) V^{-1}
$$

where $V$ is the matrix of eigenvectors of $M(t)$ and $\Lambda$ is the exponentiated matrix of eigenvalues (see Section A in the online appendix and Kalbfleisch et al. (1983) for more details).

Hypothesis 1 (Education is associated with a higher efficiency of health investment.)

$$
\begin{aligned}
& \mathrm{E}\left[P_{I D}^{(1)}(t)-P_{I D}^{(0)}(t) \mid X\right]<0 \\
& \mathrm{E}\left[P_{I H}^{(1)}(t)-P_{I H}^{(0)}(t) \mid X\right]>0
\end{aligned}
$$

where $P_{I D}^{(1)}(t)$ is the 1-year transition probability from hospitalized to death for the higher educated individuals at age $t$, and $P_{I D}^{(0)}(t)$ is the same transition probability for the lower educated. Likewise, $P_{I H}^{(k)}(t)$ refers to the transition probability from hospitalized to healthy for the higher $(k=1)$ and lower educated $(k=0)$ individuals. ${ }^{3}$ The matrix $X$ includes extensive controls for pre-existing health conditions, demographic characteristics, and hospital diagnoses.

In words, Hypothesis 1 in Eq. (4) entails that for a given hospital diagnosis, a given state of self-reported health, and conditional on demographics and social background, the higher educated individuals have a lower probability of dying.

Hypothesis 2 (Conditioning on intelligence, education does not improve the efficiency of health investment) Individuals choose their educational attainment $E$ in adolescence on the basis of their intelligence $\theta$ and other characteristics $X_{E}$. Because both $\theta$ and $X_{E}$ may additionally influence the transition probabilities, education is endogenous with respect to health investment. The central thesis of this paper is that the reason why higher educated individuals have a higher efficiency of investment derives at least partly from their higher intelligence. Therefore, we account for intelligence $\theta$ in the transition probabilities, and the empirical tests of Hypothesis 2 can be formulated as follows:

$$
\begin{aligned}
& \mathrm{E}\left[P_{I D}^{(1)}(t)-P_{I D}^{(0)}(t) \mid X, \theta\right]=0 \\
& \mathrm{E}\left[P_{I H}^{(1)}(t)-P_{I H}^{(0)}(t) \mid X, \theta\right]=0
\end{aligned}
$$

\footnotetext{
${ }^{3}$ The probability to remain in hospital, $P_{I I}$, is the complement of the two probabilities in (4) and is extremely low because the probability to be in hospital again after exactly 1 year is very low.w
} 


\section{METHODOLOGY}

Our empirical approach is an extension of the structural equation framework developed by Conti et al. (2010) and Bijwaard et al. (2015). The model consists of three parts: (i) a binary educational choice depending on latent intelligence and other covariates, (ii) potential outcomes depending on the choice of education, latent intelligence, and other covariates, and (iii) a measurement system for intelligence.

Educational choice. The binary indicator for education $E_{i}$ is defined as 1 if individual $i$ took any education beyond primary school, and 0 if not:

$$
E_{i}= \begin{cases}1 & \text { if } E_{i}^{*} \geq 0 \\ 0 & \text { otherwise }\end{cases}
$$

where we assume $E_{i}^{*}$ is an underlying latent utility, which is continuous and linear and depends on latent intelligence $\theta$, and observed characteristics $X^{E}$ :

$$
E_{i}^{*}=\gamma X_{i}^{E}+\alpha_{E} \theta_{i}+v_{i E}
$$

with $v_{E}$ being an error term independent of $X^{E}$ and $\theta$. We assume that $v_{E}$ is normally distributed, which implies that we have a probit model for the educational choice. We fix the variance at 1 because the variance is not identified in a probit model.

Multistate potential hazard outcomes. The second part is the potential outcomes part, in which there are two potential outcomes depending on whether the individual chose to pursue education beyond primary school or not. Bijwaard et al. (2015) defined the potential outcomes in terms of the mortality hazard. Our extension is a multistate model with three states: (i) healthy, (ii) hospitalized, and (iii) death, leading to four transition rates (Eq. 2), and eight potential transition rates. We define $\lambda_{H D}^{(1)}(t)$ as the mortality rate from the healthy state for an individual with education level beyond primary school $\left(E_{i}=1\right)$, and $\lambda_{H D}^{(0)}(t)$ as the mortality rate from the healthy state for an individual with an education level equal to primary school $\left(E_{i}=0\right)$. Similar definitions are used for the other transition rates.

We assume a Gompertz proportional hazard model in age for the two potential mortality rates from healthy, which has been shown to be an accurate representation of mortality between the ages of 30 and 80 (e.g. Gavrilov and Gavrilova, 1991; Cramer, 2012). Both potential hazards depend on the latent ability $\theta$ and observed characteristics while healthy $X^{H}$ :

$$
\begin{aligned}
& \lambda_{H D}^{(0)}\left(t \mid X^{H}, \theta\right)=\exp \left(a_{H D 0} t+\beta_{H D 0} X_{i}^{H}+\alpha_{H D 0} \theta_{i}\right) \\
& \lambda_{H D}^{(1)}\left(t \mid X^{H}, \theta\right)=\exp \left(a_{H D 1} t+\beta_{H D 1} X_{i}^{H}+\alpha_{H D 1} \theta_{i}\right)
\end{aligned}
$$

with $t$ age in years. The hazard of becoming hospitalized is assumed constant conditional on the individuals socio-demographics, health, and previous health investments captured in $X^{H}$

$$
\begin{aligned}
& \lambda_{H I}^{(0)}\left(t \mid X^{H}, \theta\right)=\exp \left(\beta_{H I 00}+\beta_{H I 0} X_{i}^{H}+\alpha_{H I 0} \theta_{i}\right) \\
& \lambda_{H I}^{(1)}\left(t \mid X^{H}, \theta\right)=\exp \left(\beta_{H D 10}+\beta_{H I 1} X_{i}^{H}+\alpha_{H I 1} \theta_{i}\right)
\end{aligned}
$$

Because the duration of stay in hospital is never longer than a few months, we define the transition rates from hospitalized in terms of days in hospital $(\tau)$. Both the mortality rate for the hospitalized, $\lambda_{I D}$, and the recovery rates from the hospitalized-state, $\lambda_{I H}$, are assumed to be exponential. Thus, for $k=\{H, D\}$, we have the transition rates

$$
\begin{aligned}
& \lambda_{I k}^{(0)}\left(\tau \mid X^{I}, \theta\right)=\exp \left(\beta_{I k 00}+\beta_{H I 0} X_{i}^{I}+\alpha_{I k 0} \theta_{i}\right) \\
& \lambda_{I k}^{(1)}\left(\tau \mid X^{I}, \theta\right)=\exp \left(\beta_{I k 10}+\beta_{H I 1} X_{i}^{I}+\alpha_{I k 1} \theta_{i}\right)
\end{aligned}
$$




\section{G. E. BIJWAARD AND H. VAN KIPPERSLUIS}

Measurement system for intelligence. The final part of the model is the measurement equation, linking one or two intelligence scores $M_{i k}(k=1,2)$ linearly with the discrete points of support of latent intelligence $\theta$ :

$$
M_{i k}=\delta_{k} X_{i}^{M}+\alpha_{M_{k}} \theta_{i}+v_{i} M_{k}
$$

with $v_{M_{k}}$ independent of $X^{M}$ and $\theta$. We assume that $v_{M_{k}}$ is normally distributed with variance $\sigma_{M_{k}}^{2}$. The full likelihood function is given in Appendix B.

Without additional restrictions on the distribution of the latent factors, the model is not identified. Identification of our model is closely related to the identification in a mixed proportional hazard model, where we assume, as is standard in the literature on duration models (Heckman and Singer, 1984), that the unobserved heterogeneity follows a discrete distribution with finite points of support. We assume a discrete distribution with three points of support for latent intelligence $\theta_{l}, l=1,2,3$. This is similar to including unobserved heterogeneity in the transition rates that is correlated over the different rates, and for identification, the unobserved heterogeneity needs to have a finite mean. We restrict $\theta$ to have zero mean, that is, $\sum p_{l} \theta_{l}=0$, where $p_{l}$ is the probability that $\theta=\theta_{l}$. This restricts one of the three support points $\theta_{3}$ and from the restriction that the probabilities $p_{l}$ sum up to one, the probability $p_{3}$. One additional restriction of setting $\alpha_{M_{1}}=1$ ensures identification of all $\alpha$ 's.

After estimating the transition rates in (8), (9), and (10), we calculate the 1-year transition probabilities using the one-to-one translation given by Eqs (2) and (3). Using the delta-method and the derivative of the transition matrix, we can derive the variance-covariance of the components of the transition matrix. This allows testing the theoretical Hypotheses 1 (Eq. 4) and 2 (Eq. 5).

\section{DATA AND DESCRIPTIVE STATISTICS}

The data are from a Dutch cohort born between 1937 and 1941. The survey was held in 1952 among 5823 pupils of the sixth (last) grade of primary schools in the Dutch province of Noord-Brabant and hence is referred to as the 'Brabant data'. Surveys on education in 1983 and 1993 had a response rate of around 45\%, leaving 2998 individuals. Hartog (1989) investigated the non-response for the 1983 survey and found no attrition bias in a wage analysis. The Brabant data are subsequently linked to hospitalization records for the years 1995-2005 inclusive, and the mortality register and municipality register for the years 1995-2011 inclusive. The hospital discharge register contains data on both inpatient and day care patients of all general and academic hospitals in the Netherlands. Because the administrative registers are available since 1995, only $86 \%$ of the 2998 individuals could be traced in the municipality register in 1995, leaving us with a final sample of 2579 individuals.

Endogenous variables: In the analysis, we distinguish between three states. Individuals are 'healthy'if they are alive and non-hospitalized, 'hospitalized'if they are alive but hospitalized for at least 1 day, and 'death'if they are not alive. In our sample, 409 individuals, or 16\%, died during the period 1995-2011 (of which 14\% died in hospital). Average number of hospital stays (with overnight stay) over the period 1995-2005 is 1, with more than $25 \%$ of the hospital admissions due to circulatory problems, $15 \%$ due to neoplasms, $11 \%$ due to digestive problems, and $5 \%$ due to respiratory problems.

Our main variable of interest is education, defined as the highest level of education attended, in two categories: (i) primary education (14\%), including those who attended at most (extended) ${ }^{4}$ primary school and (ii) above primary education ( $86 \%$ ), including those who attended lower vocational education, general secondary school, and higher education.

Intelligence is modeled as a latent variable. In the Brabant data, there are two separate measurements for intelligence, both measured in the final grade of primary school: (i) the IQ progressive matrices test, which focuses on mathematical ability and is a replication of the British test designed by Raven (1958), and (ii) a vocabulary test (picking synonyms). The timing of the intelligence test at age 12 years avoids possible

\footnotetext{
${ }^{4}$ At the time, pupils had to stay in school for at least 8 years, or until they reached the age of 14 years. Because regular primary school only consisted of sixth grades, some schools offered an additional 2-year extended primary school ('vglo').
} 
reverse causality from education to intelligence (Deary and Johnson, 2010). The Raven test is considered to be a 'pure' measurement of problem solving abilities, as it does not require any linguistic or general knowledge (Dronkers, 2002).

Table I. Descriptive statistics by education level

\begin{tabular}{|c|c|c|c|}
\hline & $\begin{array}{c}\text { Primary } \\
14 \%\end{array}$ & $\begin{array}{c}\text { Above primary } \\
86 \%\end{array}$ & All \\
\hline \multicolumn{4}{|l|}{ Mortality } \\
\hline Died & $23 \%$ & $15 \%$ & $16 \%$ \\
\hline$\%$ of which died in hospital & $16 \%$ & $12 \%$ & $14 \%$ \\
\hline \multicolumn{4}{|l|}{ Hospitalization } \\
\hline Number of hospital stays & 1.1 & 0.9 & 0.9 \\
\hline Emergency (acute) entry & $49 \%$ & $43 \%$ & $44 \%$ \\
\hline Length of stay (days) & 10.2 & 9.3 & 9.7 \\
\hline Repeated admittance & $44 \%$ & $38 \%$ & $39 \%$ \\
\hline \multicolumn{4}{|l|}{ Intelligence } \\
\hline Raven p.m. test & 96.29 & 103.05 & 102.04 \\
\hline Vocabulary test & 94.16 & 102.73 & 101.42 \\
\hline \multicolumn{4}{|l|}{ Diagnosis at admission } \\
\hline Neoplasm & $11 \%$ & $16 \%$ & $15 \%$ \\
\hline Circulatory & $30 \%$ & $25 \%$ & $26 \%$ \\
\hline Respiratory & $11 \%$ & $4 \%$ & $5 \%$ \\
\hline Digestive & $12 \%$ & $11 \%$ & $11 \%$ \\
\hline \multicolumn{4}{|l|}{ Control variables } \\
\hline Male & $61 \%$ & $58 \%$ & $58 \%$ \\
\hline Birth Rank & 2.82 & 2.44 & 2.50 \\
\hline \multicolumn{4}{|l|}{ Self-reported health in 1993} \\
\hline Poor & $11 \%$ & $9 \%$ & $10 \%$ \\
\hline \multicolumn{4}{|l|}{ Family socio-economic status ${ }^{\mathrm{a}}$} \\
\hline Lowest & $66 \%$ & $47 \%$ & $49 \%$ \\
\hline Middle & $23 \%$ & $45 \%$ & $41 \%$ \\
\hline Highest & $0 \%$ & $3 \%$ & $3 \%$ \\
\hline Child works & $37 \%$ & $22 \%$ & $24 \%$ \\
\hline \multicolumn{4}{|l|}{ School religion $^{\mathrm{a}}$} \\
\hline Roman Catholic & $82 \%$ & $74 \%$ & $74 \%$ \\
\hline Protestant & $14 \%$ & $19 \%$ & $19 \%$ \\
\hline Public & $4 \%$ & $7 \%$ & $7 \%$ \\
\hline Number of teachers & 6.68 & 6.95 & 6.92 \\
\hline \multicolumn{4}{|l|}{ Repeat $^{\mathrm{a}}$} \\
\hline No Repetition of grade & $33 \%$ & $66 \%$ & $61 \%$ \\
\hline Repeated once & $37 \%$ & $24 \%$ & $26 \%$ \\
\hline Repeated twice or more & $24 \%$ & $6 \%$ & $8 \%$ \\
\hline \multicolumn{4}{|l|}{ Teacher's advice ${ }^{\mathrm{a}}$} \\
\hline Continue primary school & $49 \%$ & $18 \%$ & $23 \%$ \\
\hline Lower vocational education & $37 \%$ & $35 \%$ & $36 \%$ \\
\hline Lower secondary education & $3 \%$ & $27 \%$ & $23 \%$ \\
\hline Higher secondary education & $1 \%$ & $15 \%$ & $13 \%$ \\
\hline \multicolumn{4}{|l|}{ Preference of the parents ${ }^{\mathrm{a}}$} \\
\hline Work in family company & $16 \%$ & $10 \%$ & $11 \%$ \\
\hline Paid work without vocational education & $33 \%$ & $7 \%$ & $10 \%$ \\
\hline Paid work with vocational education & $11 \%$ & $6 \%$ & $7 \%$ \\
\hline General secondary education & $19 \%$ & $65 \%$ & $58 \%$ \\
\hline
\end{tabular}

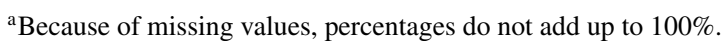


Control variables: A fairly standard set of socio-demographic control variables such age, sex (male), birth rank, and family social class is included in all equations. Family social class is measured in three categories from lowest to highest depending on father's occupation (see Bijwaard et al. 2015 for details). We additionally know whether the child had to work in the parent's farm or company, defining the binary indicator Child works.

Factors additionally influencing the measurements of intelligence, $X^{M}$, include school type and the number of teachers. Additional factors influencing the educational choice, $X^{E}$, include repeat, which defines the number of classes that children had to repeat, and finally the teacher's advice and the preference of the parents concerning the further education of the pupil (work without further education, vocational education, or general secondary education).

Finally, to test whether higher educated individuals are more efficient users of health investment, we intend to keep health status and the type of hospital diagnosis constant. Therefore, from the state healthy, the set of control variables $X^{H}$ includes self-reported health in three categories (measured in 1993), whether hospitalized before during the observation period, and the last diagnosis in case of a hospitalization (neoplasm, circulatory, respiratory, or digestive system). From the state hospitalized, the set of control variables $X^{I}$ includes self-reported health, whether it was a repeated admittance, whether it was an acute admission, and the main diagnosis of the admission. The categories of all variables are defined in Table I, which also includes descriptive statistics.

\section{RESULTS}

\subsection{Basic model without control variables}

To achieve a first impression of the impact of education on the efficiency of health investment, we start with estimating a basic model by education level without any control variables. The estimated parameters are reported in Table II. Next, we calculate the implied transition intensities, and using (3), we calculate the transition probabilities for a 1-year interval. In Figure 1, the four relevant transition probabilities are depicted. It is immediately clear that individuals who continued beyond primary education have a higher (lower) probability to recover (die) within 1 year of hospital admittance. Point estimates suggest that hospitalized individuals with a higher education have a $3 \%$ probability of dying, compared with $7 \%$ among the lower-educated individuals. From the healthy state, the probability to die within 1 year is lower, and the probability to remain healthy is higher for higher educated individuals. All these differences are statistically significant. ${ }^{5}$ This is an indication that our first hypothesis, education improves the efficiency of health investment, holds. In the remaining sections, we will only focus on the transition probability from hospital to death within 1 year, because the other transitions probabilities give very similar insights.

\subsection{Stratified model including control variables}

The previous analysis ignores that higher educated individuals have different characteristics than lowereducated individuals and that the diagnosis at hospital admission may differ too. In this section, we include the control variables discussed in Section 4 but continue to assume that the education choice is exogenous (stratified models by education level). The results correspond to Eq. (4) in the theoretical framework. Table III reports the coefficient estimates.

Table III indicates that individuals admitted with neoplasms are more likely to die (especially the higher educated individuals) and less likely to recover. Respiratory diseases also lead to less recovery and higher mortality. An emergency-admittance to the hospital increases the mortality and decreases the recovery.

Similar to the computation for the basic model, we use the estimated transition intensities from Table III to compute the transition probabilities. The left panel of Figure 2 shows that the transition probability from hospital to death by education becomes less distinct and is insignificant for young (below 70 years old) people

\footnotetext{
${ }^{5}$ The formal tests of the significance of the difference in this basic model, the stratified model, and the structural model are reported in Table C. 1 of the online appendix.
} 
EFFICIENCY OF HEALTH INVESTMENT: EDUCATION OR INTELLIGENCE?

Table II. Parameter estimates simple (no covariates included) stratified model by education level

\begin{tabular}{|c|c|c|c|c|}
\hline \multirow[b]{2}{*}{$\begin{array}{l}\text { From healthy } \\
(\log ) \text { constant }\end{array}$} & \multicolumn{2}{|c|}{ Primary education } & \multicolumn{2}{|c|}{ Above primary } \\
\hline & $\begin{array}{c}\text { To hospitalized } \\
-2.209 \\
(0.050)\end{array}$ & $\begin{array}{r}\text { To death } \\
-12.609 \\
(1.794)\end{array}$ & $\begin{array}{c}\text { To hospitalized } \\
-2.496 \\
(0.023)\end{array}$ & $\begin{array}{r}\text { To death } \\
-12.122 \\
(0.846)\end{array}$ \\
\hline Age & - & $\begin{array}{c}0.126 \\
(0.027)\end{array}$ & - & $\begin{array}{c}0.112 \\
(0.013)\end{array}$ \\
\hline $\begin{array}{l}\text { From hospitalized } \\
\text { (log) constant }\end{array}$ & $\begin{array}{c}\text { To healthy } \\
-2.357 \\
(0.051)\end{array}$ & $\begin{array}{c}\text { To death } \\
-5.748 \\
(0.277)\end{array}$ & $\begin{array}{c}\text { To healthy } \\
-2.255 \\
(0.023)\end{array}$ & $\begin{array}{c}\text { To death } \\
-6.032 \\
(0.152)\end{array}$ \\
\hline
\end{tabular}

${ }^{\text {a }}$ Duration time from healthy is years since birth.

${ }^{b}$ Duration time from hospitalized is days since hospital admission.

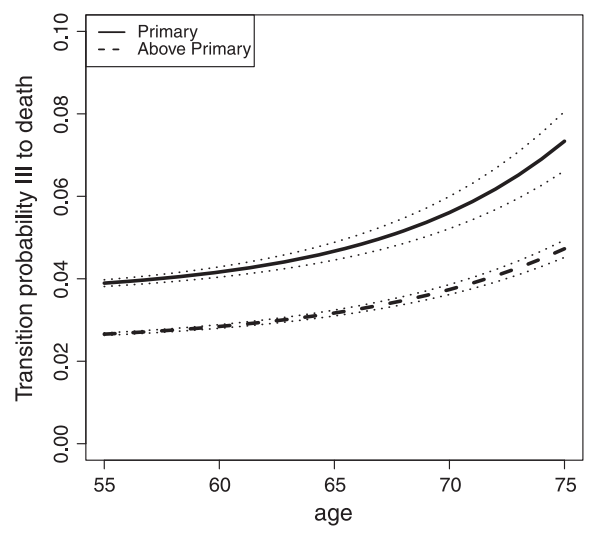

$P_{I D}$

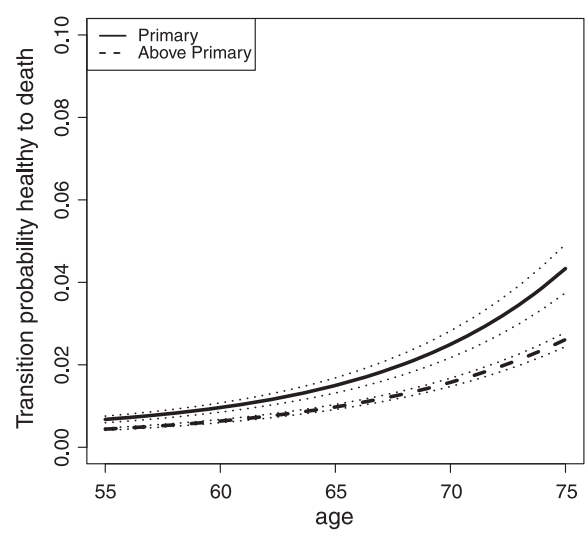

$P_{H D}$

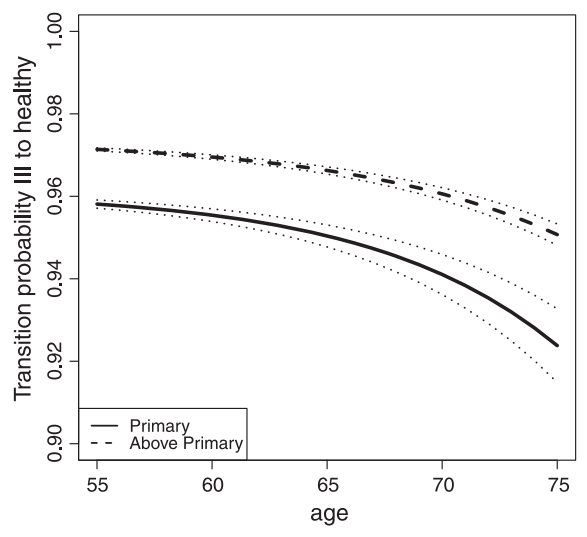

$P_{I H}$

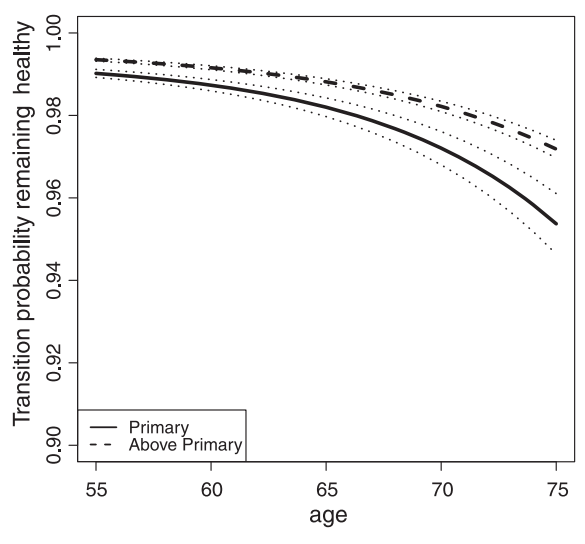

$P_{H H}$

Figure 1. Transition probability over a 1-year period (and the $95 \%$ confidence intervals) by age and education level (model without covariates)

when we condition on individual characteristics and hospital diagnosis (see Table C.1 in the online appendix). Still, individuals with only primary education have a higher probability to die within a year of hospital admittance when they are older than 70 years. Hence, we cannot reject Hypothesis 1 and confirm earlier findings that education is associated with improved efficiency of health investment, at least for those over 70 years old. 


\section{G. E. BIJWAARD AND H. VAN KIPPERSLUIS}

Table III. Parameter estimates stratified model by education level

\begin{tabular}{|c|c|c|c|c|}
\hline & \multicolumn{2}{|c|}{ Primary education } & \multicolumn{2}{|c|}{ Above primary } \\
\hline $\begin{array}{l}\text { From hospitalized }^{\mathrm{a}} \\
\text { Male }\end{array}$ & $\begin{array}{l}\text { To healthy } \\
-0.100 \\
(0.114)\end{array}$ & $\begin{array}{c}\text { To death } \\
-0.124 \\
(0.589)\end{array}$ & $\begin{array}{c}\text { To healthy } \\
0.092 \\
(0.050)\end{array}$ & $\begin{array}{c}\text { To death } \\
0.128 \\
(0.335)\end{array}$ \\
\hline \multicolumn{5}{|c|}{ Child is working - base is 'No' } \\
\hline Yes & $\begin{array}{c}-0.428^{* *} \\
(0.117)\end{array}$ & $\begin{array}{c}0.299 \\
(0.650)\end{array}$ & $\begin{array}{c}0.077 \\
(0.056)\end{array}$ & $\begin{array}{r}-0.736 \\
(0.453)\end{array}$ \\
\hline Missing & $\begin{array}{c}0.072 \\
(0.220)\end{array}$ & $\begin{array}{r}-0.017 \\
(1.162)\end{array}$ & $\begin{array}{r}-0.069 \\
(0.085)\end{array}$ & $\begin{array}{c}-1.081 \\
(0.667)\end{array}$ \\
\hline \multicolumn{5}{|c|}{ Birthrank - base is 'First' } \\
\hline Second & $\begin{array}{c}0.059 \\
(0.194)\end{array}$ & - & $\begin{array}{c}-0.071 \\
(0.072)\end{array}$ & $\begin{array}{c}-0.918^{+} \\
(0.451)\end{array}$ \\
\hline Third or fourth & $\begin{array}{c}0.004 \\
(0.177)\end{array}$ & - & $\begin{array}{c}-0.169^{* *} \\
(0.067)\end{array}$ & $\begin{array}{r}-0.009 \\
(0.491)\end{array}$ \\
\hline Fifth or higher & $\begin{array}{c}0.007 \\
(0.183)\end{array}$ & - & $\begin{array}{c}-0.201^{* *} \\
(0.065)\end{array}$ & $\begin{array}{c}0.261 \\
(0.461)\end{array}$ \\
\hline Missing & $\begin{array}{c}-0.190 \\
(0.273)\end{array}$ & - & $\begin{array}{c}-0.380^{* *} \\
(0.122)\end{array}$ & $\begin{array}{c}0.664 \\
(0.844)\end{array}$ \\
\hline \multicolumn{5}{|c|}{ Health status in 1993 - base is 'good' } \\
\hline Poor health & $\begin{array}{c}0.077 \\
(0.129)\end{array}$ & $\begin{array}{c}0.274 \\
(0.630)\end{array}$ & $\begin{array}{c}-0.172^{* *} \\
(0.064)\end{array}$ & $\begin{array}{c}-0.204 \\
(0.435)\end{array}$ \\
\hline \multicolumn{5}{|c|}{ Previous hospitalization and last diagnosis } \\
\hline Repeated admittance & $\begin{array}{c}-0.036 \\
(0.107)\end{array}$ & $\begin{array}{c}1.127 \\
(0.783)\end{array}$ & $\begin{array}{l}-0.110^{+} \\
(0.047)\end{array}$ & $\begin{array}{c}0.556 \\
(0.338)\end{array}$ \\
\hline Neoplasm & $\begin{array}{c}-0.331 \\
(0.187)\end{array}$ & $\begin{array}{l}1.419^{+} \\
(0.657)\end{array}$ & $\begin{array}{l}-0.313^{* *} \\
(0.069)\end{array}$ & $\begin{array}{l}2.695^{* *} \\
(0.502)\end{array}$ \\
\hline Circulatory & $\begin{array}{c}0.044 \\
(0.139)\end{array}$ & $\begin{array}{c}0.645 \\
(0.796)\end{array}$ & $\begin{array}{c}-0.033 \\
(0.061)\end{array}$ & $\begin{array}{c}0.692 \\
(0.580)\end{array}$ \\
\hline Respiratory & $\begin{array}{c}-0.413^{+} \\
(0.200)\end{array}$ & - & $\begin{array}{c}0.145 \\
(0.118)\end{array}$ & $\begin{array}{l}1.545^{* *} \\
(0.739)\end{array}$ \\
\hline Digestive & $\begin{array}{c}0.069 \\
(0.168)\end{array}$ & - & $\begin{array}{l}0.263^{* *} \\
(0.079)\end{array}$ & $\begin{array}{c}-1.317 \\
(0.675)\end{array}$ \\
\hline Acute & $\begin{array}{c}-0.428^{* *} \\
(0.106)\end{array}$ & $\begin{array}{c}1.270 \\
(0.778)\end{array}$ & $\begin{array}{c}-0.365^{* *} \\
(0.049)\end{array}$ & $\begin{array}{l}1.410^{* *} \\
(0.361)\end{array}$ \\
\hline$(\log )$ constant & $\begin{array}{r}-1.772 \\
(0.211)\end{array}$ & $\begin{array}{c}-8.183 \\
(1.158)\end{array}$ & $\begin{array}{r}-1.912 \\
(0.072)\end{array}$ & $\begin{array}{r}-8.736 \\
(0.709)\end{array}$ \\
\hline $\begin{array}{l}\text { From healthy } \\
\text { Male }\end{array}$ & $\begin{array}{l}\text { To hospitalized } \\
\quad-0.212 \\
(0.109)\end{array}$ & $\begin{array}{c}\text { To death } \\
0.727^{* *} \\
(0.289)\end{array}$ & $\begin{array}{c}\text { To hospitalized } \\
0.179^{* *} \\
(0.049)\end{array}$ & $\begin{array}{c}\text { To death } \\
0.717^{* *} \\
(0.137)\end{array}$ \\
\hline \multicolumn{5}{|c|}{ Child is working - base is 'No' } \\
\hline Yes & $\begin{array}{c}0.071 \\
(0.114)\end{array}$ & $\begin{array}{c}0.124 \\
(0.272)\end{array}$ & $\begin{array}{l}0.136^{+} \\
(0.055)\end{array}$ & $\begin{array}{c}0.240 \\
(0.147)\end{array}$ \\
\hline Missing & $\begin{array}{r}-0.352 \\
(0.213)\end{array}$ & $\begin{array}{r}-1.124 \\
(0.617)\end{array}$ & $\begin{array}{c}-0.114 \\
(0.083)\end{array}$ & $\begin{array}{c}0.181 \\
(0.200)\end{array}$ \\
\hline \multicolumn{5}{|c|}{ Family socio-economic status - base is 'Low' } \\
\hline Middle & $\begin{array}{r}-0.084 \\
(0.133)\end{array}$ & $\begin{array}{r}-0.097 \\
(0.328)\end{array}$ & $\begin{array}{r}-0.040 \\
(0.049)\end{array}$ & $\begin{array}{c}0.135 \\
(0.128)\end{array}$ \\
\hline High & $\begin{array}{r}-0.084 \\
(0.133)\end{array}$ & $\begin{array}{r}-0.097 \\
(0.328)\end{array}$ & $\begin{array}{c}0.217 \\
(0.131)\end{array}$ & $\begin{array}{c}0.540 \\
(0.318)\end{array}$ \\
\hline Missing & $\begin{array}{c}-0.492^{+} \\
(0.244)\end{array}$ & $\begin{array}{c}-0.787 \\
(0.674)\end{array}$ & $\begin{array}{c}0.013 \\
(0.123)\end{array}$ & $\begin{array}{c}0.377 \\
(0.318)\end{array}$ \\
\hline $\begin{array}{l}\text { Birthrank - base is ' } \mathrm{Fi} \\
\text { Second }\end{array}$ & $\begin{array}{c}0.175 \\
(0.185)\end{array}$ & $\begin{array}{r}-0.589 \\
(0.409)\end{array}$ & $\begin{array}{c}0.016 \\
(0.071)\end{array}$ & $\begin{array}{r}-0.130 \\
(0.176)\end{array}$ \\
\hline
\end{tabular}

${ }^{\text {a}}$ Duration time from hospitalized is days since hospital admission.

$+p<0.05$ and $^{* *} p<0.01$. 
EFFICIENCY OF HEALTH INVESTMENT: EDUCATION OR INTELLIGENCE?

Table III. (Continued)

\begin{tabular}{|c|c|c|c|c|}
\hline \multirow[b]{2}{*}{ Third or Fourth } & \multicolumn{2}{|c|}{ Primary education } & \multicolumn{2}{|c|}{ Above primary } \\
\hline & $\begin{array}{l}0.453^{* *} \\
(0.165)\end{array}$ & $\begin{array}{r}-0.328 \\
(0.375)\end{array}$ & $\begin{array}{c}0.026 \\
(0.066)\end{array}$ & $\begin{array}{c}-0.195 \\
(0.167)\end{array}$ \\
\hline Fifth or higher & $\begin{array}{c}0.385^{+} \\
(0.170)\end{array}$ & $\begin{array}{c}-0.074 \\
(0.357)\end{array}$ & $\begin{array}{c}0.073 \\
(0.065)\end{array}$ & $\begin{array}{r}-0.312 \\
(0.171)\end{array}$ \\
\hline Missing & $\begin{array}{l}0.768^{* *} \\
(0.292)\end{array}$ & $\begin{array}{c}0.848 \\
(0.655)\end{array}$ & $\begin{array}{c}0.027 \\
(0.131)\end{array}$ & $\begin{array}{c}-0.681 \\
(0.374)\end{array}$ \\
\hline \multicolumn{5}{|c|}{ Health status in 1993 - base is 'good' } \\
\hline Poor health & $\begin{array}{l}0.419^{* *} \\
(0.149)\end{array}$ & $\begin{array}{r}-0.604 \\
(0.519)\end{array}$ & $\begin{array}{l}0.445^{* *} \\
(0.066)\end{array}$ & $\begin{array}{c}0.317 \\
(0.189)\end{array}$ \\
\hline Missing & $\begin{array}{c}-0.121 \\
(0.123)\end{array}$ & $\begin{array}{c}0.420 \\
(0.294)\end{array}$ & $\begin{array}{c}0.042 \\
(0.053)\end{array}$ & $\begin{array}{c}0.186 \\
(0.137)\end{array}$ \\
\hline \multicolumn{5}{|c|}{ Hospitalization and last diagnosis } \\
\hline Has been in hospital & $\begin{array}{l}1.194^{* *} \\
(0.135)\end{array}$ & $\begin{array}{c}0.663^{+} \\
(0.299)\end{array}$ & $\begin{array}{l}1.351^{* *} \\
(0.056)\end{array}$ & $\begin{array}{c}0.988^{* *} \\
(0.142)\end{array}$ \\
\hline Neoplasm & $\begin{array}{l}0.789^{* *} \\
(0.218)\end{array}$ & $\begin{array}{l}1.576^{* *} \\
(0.537)\end{array}$ & $\begin{array}{l}1.109^{* *} \\
(0.082)\end{array}$ & $\begin{array}{l}1.659^{* *} \\
(0.176)\end{array}$ \\
\hline Circulatory & $\begin{array}{l}0.404^{* *} \\
(0.161)\end{array}$ & $\begin{array}{c}0.114 \\
(0.428)\end{array}$ & $\begin{array}{l}0.444^{* *} \\
(0.071)\end{array}$ & $\begin{array}{c}0.302 \\
(0.187)\end{array}$ \\
\hline Respiratory & $\begin{array}{l}1.047^{* *} \\
(0.208)\end{array}$ & $\begin{array}{l}1.696^{* *} \\
(0.491)\end{array}$ & $\begin{array}{l}0.475^{* *} \\
(0.141)\end{array}$ & $\begin{array}{c}0.143 \\
(0.421)\end{array}$ \\
\hline Digestive & $\begin{array}{c}0.148 \\
(0.207)\end{array}$ & $\begin{array}{r}-0.060 \\
(0.557)\end{array}$ & $\begin{array}{c}-0.155 \\
(0.110)\end{array}$ & $\begin{array}{c}-0.186 \\
(0.278)\end{array}$ \\
\hline$(\log )$ constant & $\begin{array}{c}-2.992 \\
(0.189)\end{array}$ & $\begin{array}{r}-13.325 \\
(1.933)\end{array}$ & $\begin{array}{r}-3.318 \\
(0.069)\end{array}$ & $\begin{array}{r}-11.584 \\
(0.902)\end{array}$ \\
\hline Age & - & $\begin{array}{c}0.125 \\
(0.028)\end{array}$ & - & $\begin{array}{c}0.087 \\
(0.014)\end{array}$ \\
\hline
\end{tabular}

${ }^{\text {a }}$ Duration time from healthy is years since birth.

$+p<0.05$ and ${ }^{* *} p<0.01$.
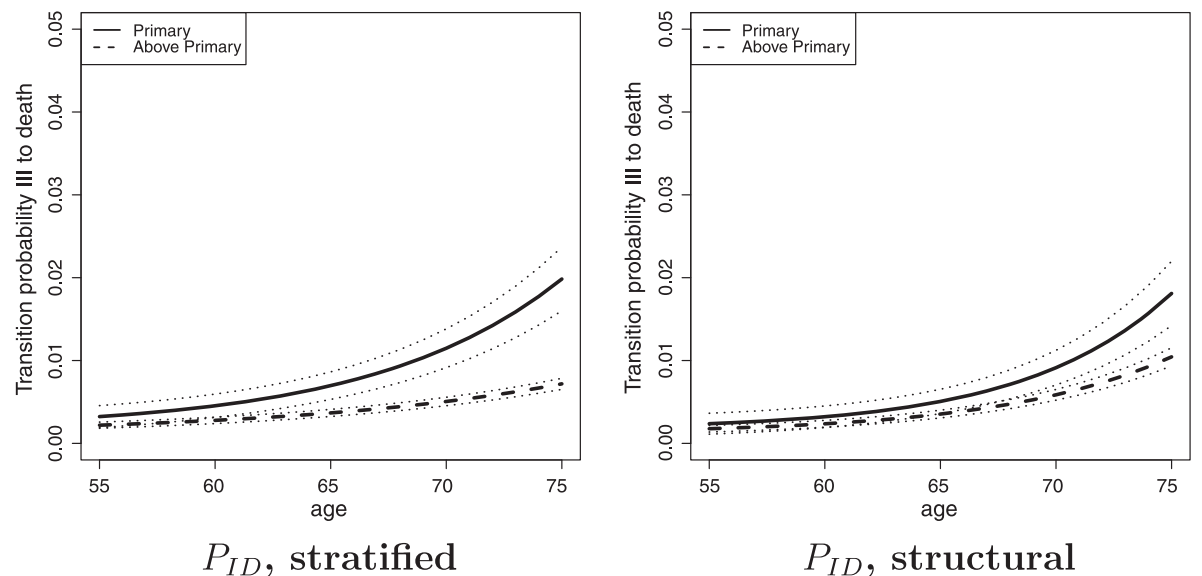

Figure 2. Transition probability over a 1-year period (and the $95 \%$ confidence intervals) from hospitalized to death by education level (stratified and structural model)

\subsection{Structural model including intelligence}

Next, we estimate the full structural model in which both the education choice and the transition rates depend on latent intelligence, corresponding to Eq. (5) in the theoretical framework. Table IV reports the parameter estimates of the structural model. The coefficients for the control variables are very similar to the estimated 
Table IV. Parameter estimates structural model by education level

\begin{tabular}{|c|c|c|c|c|}
\hline & \multicolumn{2}{|c|}{ Primary education } & \multicolumn{2}{|c|}{ Above primary } \\
\hline \multicolumn{5}{|c|}{ Transition rates from hospitalized ${ }^{\mathrm{b}}$} \\
\hline & to healthy & to death & to healthy & to death \\
\hline Intelligence & $0.092^{+}$ & 0.238 & $0.116^{* *}$ & 0.129 \\
\hline & $(0.044)$ & $(0.183)$ & $(0.038)$ & $(0.138)$ \\
\hline$(\log )$ constant & -1.576 & -7.983 & -1.837 & -8.626 \\
\hline \multicolumn{5}{|c|}{ Transition rates from healthy } \\
\hline & to hospitalized & to death & to hospitalized & to death \\
\hline Intelligence & $-0.537^{* *}$ & -0.142 & & \\
\hline$(\log )$ constant & $\begin{array}{l}(0.159) \\
-3.779\end{array}$ & -15.990 & -3.396 & -14.901 \\
\hline & $(0.366)$ & $(2.164)$ & $(0.088)$ & (1.069) \\
\hline Age & - & $\begin{array}{c}0.159 \\
(0.031)\end{array}$ & - & $\begin{array}{c}0.137 \\
(0.016)\end{array}$ \\
\hline \multicolumn{5}{|c|}{ Educational choice } \\
\hline & Education $^{\mathrm{c}}$ & Raven test ${ }^{\mathrm{d}}$ & & \\
\hline Intelligence & $\begin{array}{c}0.137^{+} \\
(0.063)\end{array}$ & 1 & & \\
\hline \multicolumn{5}{|c|}{ Measurement system } \\
\hline \multicolumn{3}{|c|}{$\theta_{1}$} & $\begin{array}{r}-5.310 \\
(1.525)\end{array}$ & \\
\hline \multicolumn{2}{|l|}{$\theta_{2}$} & & $\begin{array}{c}0.426 \\
(0.129)\end{array}$ & \\
\hline$\theta_{3}$ & & & $\begin{array}{c}-2.628 \\
(0.758)\end{array}$ & \\
\hline$p_{1}$ & & & $\begin{array}{c}0.012 \\
(0.003)\end{array}$ & \\
\hline$p_{2}$ & & & $\begin{array}{c}0.871 \\
(0.002)\end{array}$ & \\
\hline$p_{3}$ & & & $\begin{array}{l}0.118 \\
(0.015)\end{array}$ & \\
\hline
\end{tabular}

${ }^{\mathrm{b}}$ Duration time from hospitalized is days since hospital admission.

${ }^{\mathrm{c}}$ Education choice probit model.

${ }^{\mathrm{d}}$ IQ-measurement linear model, centered around $\mathrm{IQ}=100$.

$+p<0.05$ and ${ }^{* *} p<0.01$.

coefficients for the transition rates in the stratified model in Table III and are therefore only reported in online Appendix Table C.2. Intelligence significantly affects the educational choice, and virtually all transition rates. Intelligence does not significantly affect the transition rate from hospitalized to death but recall that the transition probability depends also on the transition rates from the healthy state (Eq. 3), for which the coefficient of intelligence is always in the expected direction and with one exception statistically significant.

The transition probabilities from hospital to death (and the 95\% confidence intervals) are depicted in the right panel of Figure 2. We see that the difference between the two education groups has dropped after accounting for the effect of intelligence. The difference between the education levels is now for the whole age range insignificant (see Table C.1 in the online Appendix). Because the only difference between the left and right panel of Figure 2 is the addition of intelligence in the right panel, we conclude that accounting for intelligence removes most of the difference in the efficiency of health investment between higher and lower educated individuals.

\subsection{Heterogeneity in diagnosis}

We included four different diagnoses at hospital admission in our model. Figure 3 shows the transition probability to die within 1 year after admission for these four different diagnoses. When people enter hospital and are 

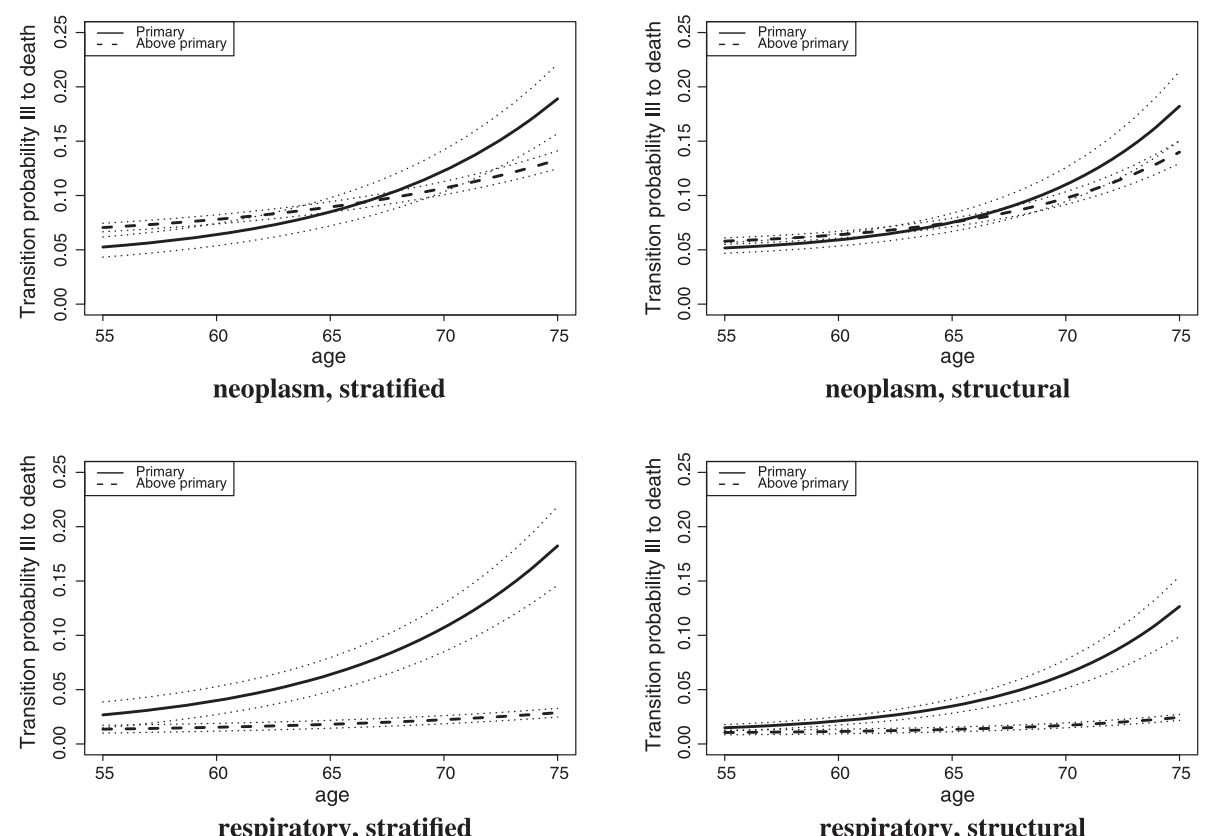

respiratory, structural
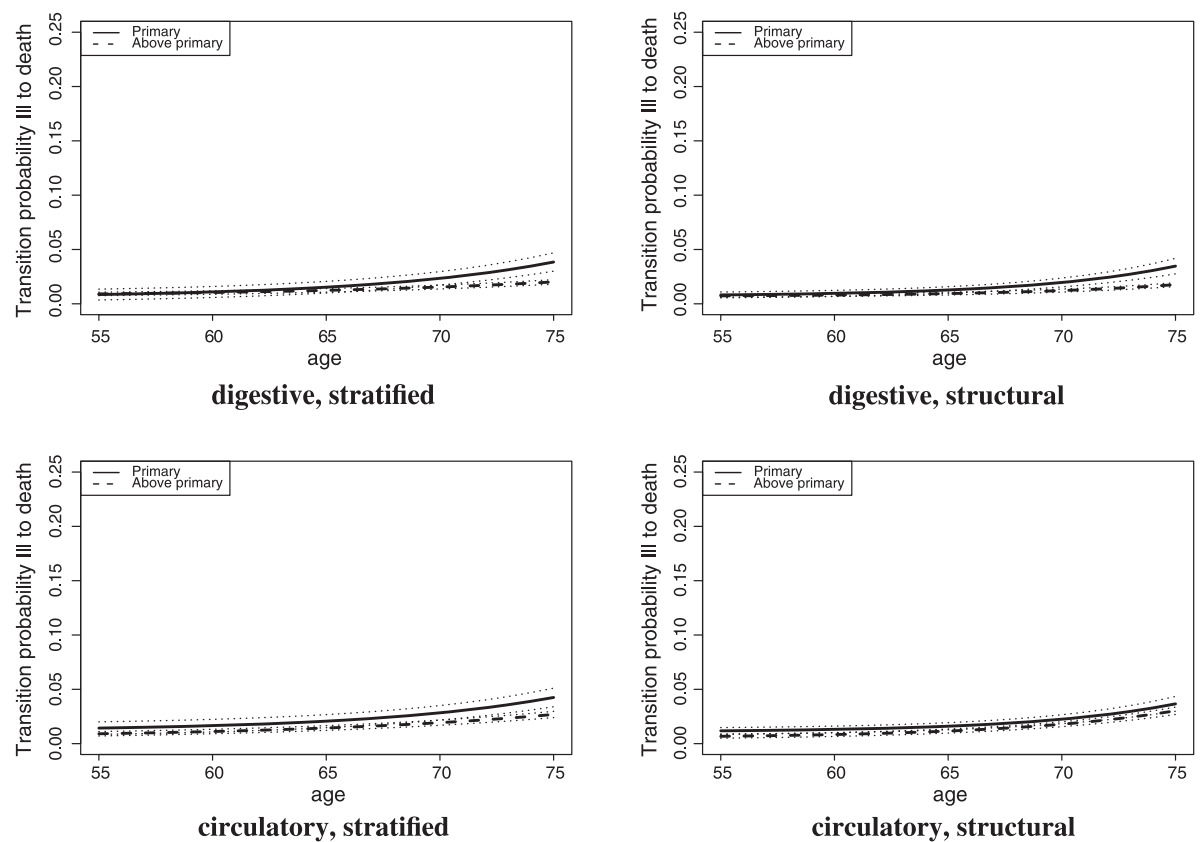

Figure 3. Transition probability from hospitalized to death over a 1-year period by age and education level (stratified and structural model): DIAGNOSES

diagnosed with cancer, survival is the same for higher and lower educated individuals. The small efficiency gain of the higher educated individuals at higher ages is removed after controlling for intelligence. On the contrary, for respiratory diseases (COPD and pneumonia), we find a large educational gain of survival after hospitalization, especially at later ages, which is only marginally reduced after controlling for intelligence. A 75-year-old 
individual with only primary education admitted to hospital with a respiratory diseases has a $13 \%$ chance to die within a year, while a higher educated individual aged 75 years with a respiratory disease has only $3 \%$ chance to die. Digestive and circulatory diseases have much lower mortality and show only a marginal gain in health efficiency by education.

This evidence suggests that when confronted with a respiratory disease, the higher educated individuals are in fact more efficient users of health investment. However, this conclusion is contingent on the assumption that there is no variation in the type and severity of illness within the broader group of respiratory admissions. Unfortunately, the sample size does not permit controlling for even finer levels of diagnoses. Nonetheless, we did check the exact International Classification of Diseases 9 codes within the larger diagnose groups; see Table V. It follows that for circulatory and digestive diseases, the sub-diagnoses are very similar across educational groups (e.g., coronary atherosclerosis or angina pectoris in the case of circulatory diseases and inguinal hernia and gallbladder in case of digestive diseases). The differences in proportions across educational groups are all insignificant at 5\%, except for one specific code of digestive disease.

For neoplasms and respiratory diseases, however, differences do exist. Neoplasms among the lower-educated individials are more often metastases. For respiratory diseases, the lower-educated individuals are significantly more likely to be admitted for COPD, while higher educated individuals suffer more often from pneumonia and milder lung diseases. This suggests that the 'efficiency gain' we observed among the higher educated individuals for respiratory diseases is likely to stem largely from different diagnoses and the severity of illness rather than a true survival gain for a given diagnosis.

Table V. ICD 9 Codes for broader class of diagnoses

\begin{tabular}{|c|c|c|c|}
\hline ICD 9 code & Diagnosis & Primary education & Above primary \\
\hline Neoplasms & & $N=122$ & $N=699$ \\
\hline 154 & Rectum cancer & & $15 \% *$ \\
\hline 162 & Lung cancer & $10 \%$ & $6 \%$ \\
\hline 174 & Breast cancer (female) & & $7 \%$ \\
\hline 197 & Metastasis to respiratory and digestive systems & $8 \%$ & $14 \% *$ \\
\hline 198 & Metastasis to kidney & $38 \%$ & $3 \% *$ \\
\hline \multicolumn{2}{|c|}{ Circulatory diseases } & $N=191$ & $N=860$ \\
\hline 410 & Acute myocardial infaction & $6 \%$ & $11 \%$ \\
\hline 411 & Postmyorcardial infarction syndrome & $10 \%$ & $7 \%$ \\
\hline 413 & Angina pectoris & $10 \%$ & $10 \%$ \\
\hline 414 & Atherosclerosis & $19 \%$ & $22 \%$ \\
\hline 427 & Atrial fibrillation & $10 \%$ & $9 \%$ \\
\hline 428 & Heart failure & $6 \%$ & $3 \%$ \\
\hline 454 & Varicose veins & & $5 \%$ \\
\hline \multicolumn{2}{|c|}{ Respiratory diseases } & $N=55$ & $N=138$ \\
\hline 473 & Chronic sinusitis & & $7 \%$ \\
\hline 478 & Other diseases of upper respiratory tract & & $14 \% *$ \\
\hline 486 & Pneumonia & & $12 \%$ \\
\hline 491 & Chronic bronchitis & $16 \%$ & $*$ \\
\hline 492 & Emphysema & $16 \%$ & * \\
\hline 496 & COPD (unspecified) & $20 \%$ & $14 \%$ \\
\hline \multicolumn{2}{|c|}{ Diseases of the digestive system } & $N=70$ & $N=354$ \\
\hline 550 & Inguinal hernia & $13 \%$ & $22 \%$ \\
\hline 553 & Other hernia of abdominal cavity & $16 \%$ & $8 \% *$ \\
\hline 562 & Diverticula of intestine & & $5 \%$ \\
\hline 574 & Gallbladder & & $16 \%$ \\
\hline
\end{tabular}

Note: Specific ICD 9 codes for the larger group of diagnoses. Note that because of privacy regulations, we are not allowed to reveal the percentages for which the cell count is less than 10 . We did take these percentages into account when testing for significant differences. A star $(*)$ indicates that the proportions differ significantly at $5 \%$ across the two groups.

ICD, International Classification of Diseases. 


\subsection{Robustness checks}

In this section, we present a couple of robustness checks, results of which are all available in online Appendix C. First, there could be gender differences. The educational gains for females are indeed higher for women than for men. Still, after accounting for intelligence, these gains are insignificant.

Second, while the inclusion of the variables in $X^{H}$ and $X^{I}$, such as self-reported health and (previous) hospital admissions, allows investigating efficiency gains for a given health status and hospital diagnosis, one may be worried that the endogeneity of these variables leads to a bias in the comparison of transition probabilities across educational groups. Therefore, we re-estimated all models excluding these potentially endogenous variables, and results are very similar.

Third, we tested robustness to the definition of the educational choice. We re-defined education as comprising three levels, where we split the higher educated individuals further into lower vocational education or general secondary education, and higher vocational/university. While there are some differences across the secondary and higher education groups, we find that the largest disparity is between those attending only primary education and the rest. This gives comfort that our binary representation of education is justified.

Fourth, in the base Gompertz model, we assume that the transitions are constant with respect to age, conditional on the health status and previous diagnoses of the individual. When estimating piecewise constant models without the previous diagnoses, the age dependence is positive and statistically significant. When adding the previous diagnoses, the age dependence of the transitions hazards is very limited and, in some cases, even negative. This suggests that previous diagnoses account for the age dependence in the transitions, and constant durations are a reasonable assumption. Importantly, including or excluding the duration dependence does not change any of our conclusions.

Finally, apart from the Raven test, we have estimated models in which we added an additional measurement for intelligence, namely, the vocabulary test. Because efficiency of health investment may in part derive from verbal and communication skills, it is worth extending the definition of intelligence to include this component too. The results prove robust to adding the vocabulary test.

\section{DISCUSSION}

Higher educated individuals are healthier and live longer than their lower-educated peers. In this paper, we formulate two testable hypotheses regarding the sources of these disparities: (i) education is associated with a higher efficiency of health investment, and (ii) conditional on intelligence, education does not improve the efficiency of health investment. In line with Kenkel (1995) and Gilleskie and Harrison (1998), we find evidence for an association between education and the efficiency of health investment: Higher educated individuals are less likely to die during middle-age after a hospitalization. These results hold even for a given health status and given a certain diagnosis. Hence, we cannot reject our first hypothesis. Yet in contrast to these studies, we challenge the interpretation that education itself drives the efficiency of health investment: When accounting for the role of intelligence using a structural equation model, the association between education and the efficiency of health investment disappears. This suggests that intelligence accounts for a substantial proportion of the survival advantage of higher educated individuals, consistent with evidence by Conti et al. (2010) and Bijwaard et al. (2015).

Analyses investigating heterogeneity in the effects further suggest that the relative impact of education compared to intelligence is stronger for respiratory diseases. While it is tempting to attribute this to education having efficiency gains in terms of adhering to complex treatment regimens for diseases like COPD, a detailed analysis of the exact International Classification of Diseases 9 diagnoses reveals that the type of respiratory diseases contracted by higher and lower educated individuals differs. Hence, the survival gain for the higher educated individuals derives at least partially from a different severity of illness. For other diseases, the diagnoses do largely reflect the same type of diseases across educational groups, suggesting that we can interpret any survival differences as being due to health investment efficiency. For those diagnoses we find that survival gains among the higher educated individuals evaporate when conditioning on intelligence. Taken together, we 
conclude that conditional on intelligence, and the hospital diagnosis, education is not associated with a higher efficiency of health investment.

Most important limitation of our paper is the lack of measures for childhood health status and non-cognitive skills. A recent survey by Heckman (2012) suggests the importance of personality traits and children's health endowment on their health outcomes as adults. The omission of these variables could therefore bias our estimates. While we do not have measures for childhood health status, it seems reasonable to assume that, conditional on cognitive abilities, the teacher's advice regarding the secondary education of the child is a proxy for non-cognitive abilities. The results from a model allowing teacher's advice additionally to influence the transitions rates are however very close to our original results, suggesting that the omission of non-cognitive abilities is unlikely to change our main conclusion that intelligence drives most of the efficiency gains associated with education.

In terms of policy implications, because intelligence is more important than education for the efficiency of health investment, nudging policies that alters people's behavior without forcing them (Thaler and Sunstein, 2008) may provide health improvements for all education and intelligence levels. Because nudging can change behavior non-deliberately, thus without using the cognitive system, it could offer new possibilities for encouraging efficient use of health investment to improve survival chances among the least cognitively able. A specific example could be changing the default option for breathing exercise for COPD patients from 1 year to half a year, and excluding it from the deductible. In this way, the least cognitively able patients are stimulated and actively assisted to adhere to complex self-care regimes without forcing them or erecting financial barriers.

\section{ACKNOWLEDGEMENTS}

Van Kippersluis gratefully acknowledges funding from the National Institute on Aging (NIA) under grant R01AG037398 and from the Netherlands Organization of Scientific Research (NWO Veni grant 016.145.082). The authors acknowledge access to linked data resources (DO 1995-2011, LMR 1995-2005) by Statistics Netherlands (CBS). Further, they are grateful to two anonymous referees, Raphael Guber, attendants at the European Workshop on Econometrics and Health Economics in Paris 2015 at the NIDI/RUG workshop Early life circumstances and late life outcomes 2015, at the Multistate Event History Analysis conference in Hangzhou, the Health, Education and Retirement over the Prolonged Life Cycle conference in Vienna, the Dutch Demography day, and at a seminar at the University of Gent for helpful comments.

\section{REFERENCES}

Albouy V, Lequien L. 2009. Does compulsory education lower mortality? Journal of Health Economics 28(1): 155-168. Auld CM, Sidhu N. 2005. Schooling, cognitive ability, and health. Health Economics 14: 1019-1034.

Bijwaard GE, van Kippersluis H, Veenman J. 2015. Education and health: the role of cognitive ability. Journal of Health Economics 42: 29-43.

Clark D, Royer H. 2013. The effect of education on adult mortality and health: evidence from Britain. American Economic Review 103(6): 2087-2120.

Conti G, Heckman JJ. 2010. Understanding the early origins of the education-health gradient: a framework that can also be applied to analyze gene-environment interactions. Perspectives on Psychological Science 5(5): 585-605.

Conti G, Heckman JJ, Urzua S. 2010. The education-health gradient. American Economic Review Papers and Proceedings 100: $234-238$.

Cramer JS. 2012. Childhood intelligence and adult mortality, and the role of socio-economic status. Tinbergen Institute Discussion Paper 2012-070/4.

Cutler D, Lleras-Muney A. 2008. Education and health: evaluating theories and evidence, In Making Americans Healthier: Social and Economic Policy as Health Policy, House JS, Schoeni RF, Kaplan GA, Pollack H (eds). Russell Sage Foundation: New York.

Deary I, Johnson W. 2010. Intelligence and education: causal perceptions drive analytic processes and therefore conclusions. International Journal of Epidemiology 39: 1362-1369.

Dronkers J. 2002. Bestaat er een samenhang tussen echtscheiding en intelligentie? Mens \& Maatschappij 77(1): $25-42$. 
Gavrilov LA, Gavrilova NS. 1991. The Biology of Life Span: A Quantitative Approach. Harwood Academic Publisher: New York. ISBN 3-7186-4983-7.

Gilleskie DB, Harrison AL. 1998. The effect of endogenous health inputs on the relationship between health and education. Economics of Education Review 17(3): 279-295.

Glied S, Lleras-Muney A. 2008. Technological innovation and inequality in health. Demography 45(3): $741-761$.

Goldman DP, Smith JP. 2002. Can patient self-management help explain the SES health gradient? Proceedings of the National Academy of Science 99: 10929-10934.

Goldman DP, Lakdawalla DN. 2005. A theory of health disparities and medical technology. The B.E. Journal of Economic Analysis \& Policy 4(1): 1-32.

Gottfredson LS, Deary IJ. 2004. Intelligence predicts health and longevity, but why? Current Directions in Psychological Science 13(1): 1-4.

Griliches Z. 1977. Estimating the returns to schooling - some econometric problems. Econometrica 45(1): 1-22.

Grossman M. 1972. On the concept of health capital and the demand for health. Journal of Political Economy 80(2): 223255.

Grossman M. 2006. Education and non-market outcomes, In Handbook of the Economics of Education, Hanushek E, Welch F (eds)., Chapter 10, vol. 1, Elsevier: Amsterdam; 577-633.

Grossman M. 2015. The relationship between health and schooling: what's new? Nordic Journal of Health Economics 3(1): $7-17$.

Hartog J. 1989. Survey non-response in relation to ability and family background: structure and effects on estimated earnings functions. Applied Economics 21: 387-395.

Heckman JJ, Humphries JE, Veramendi G, Urzua S. 2014. Education, health, and wages, NBER Working Paper No. 19971.

Heckman JJ. 2012. The developmental origins of health. Health Economics 21: 24-29.

Heckman JJ, Singer B. 1984. A method for minimizing the impact of distributional assumptions in econometric models for duration data. Econometrica 52: 271-320.

Kaestner R, Callison K. 2011. Adolescent cognitive and non-cognitive correlates of adult health. Journal of Human Capital 5(1): 29-69.

Kalbfleisch JD, Lawless JF, Vollmer WM. 1983. Estimation in Markov models from aggregate data. Biometrics 39: 907-919.

Kenkel DS. 1991. Health behavior, health knowledge, and schooling. Journal of Political Economy 99(2): $287-305$.

Kenkel DS. 1995. Should you eat breakfast? Estimates from health production functions. Health Economics 4(1): 15-29.

Lange F. 2011. The role of education in complex health decisions: evidence from cancer screening. Journal of Health Economics 30(1): 43-54.

Lleras-Muney A. 2005. The relationship between education and adult mortality in the United States. Review of Economic Studies 72: 189-221.

Lleras-Muney A, Lichtenberg F. 2005. Are the more educated more likely to use new drugs. Annales d'Economie et Statistique in memory of Zvi Griliches 80: 671-696.

Mazumder B. 2012. The effects of education on health and mortality. Nordic Economic Policy Review 1: $261-301$.

Meara E, Richards S, Cutler DM. 2008. The gap gets bigger: changes in mortality and life expectancy, by education, 1981-2000. Health Affairs 27(2): 350-360.

Meghir C, Palme M, Simeonova E. 2013. Education, cognition and health: evidence from a social experiment, NBER Working Paper 19002.

Michael RT, Becker GS. 1973. On the new theory of consumer behavior. The Swedish Journal of Economics 75(4): 378-396.

Murphy KM, Topel RH. 2006. Journal of Political Economy 114(5): 871-904.

Muurinen J-M. 1982. Demand for health: a generalized Grossman model. Journal of Health Economics 1: 5-28.

Raven JC. 1958. Mill Hill Vocabulav Scale (2nd edn). H. K. Lewis: London.

Rosenzweig MR, Schultz TP. 1981. Education and household production of child health. Proceedings of the American Statistical Association, Social Statistical Section, American Statis. Assoc: Washington; 382-387.

Thaler RH, Sunstein CR. 2008. Nudge: Improving Decisions About Health, Wealth, and Happiness. Yale University Press: Yale.

Van Kippersluis H, O’Donnell O, van Doorslaer E. 2011. Long run returns to education: does schooling lead to an extended old age? Journal of Human Resources 46(4): 695-721.

\section{SUPPORTING INFORMATION}

Additional Supporting Information may be found in the online version of this article at the publisher's web site. 